\title{
RETRACTED: Minimum makespan task scheduling algorithm in cloud computing
}

\author{
N. Sasikaladevi \\ School of Computing, SASTRA University, India \\ sasikalade@gmail.com
}

ARTICLE INFO

RETRACTED

Article history:

Retraction notice to "Minimum makespan

task scheduling algorithm in cloud

computing", Vol 2, No 3, pp. 123-130,

November 2016

DOI: http://dx.doi.org/10.26555/ijain.v2i3.59
Following a rigorous, carefully concerns and considered review of the article published in International Journal of Advances in Intelligent Informatics to article entitled "Minimum makespan task scheduling algorithm in cloud computing" Vol 2, No 3, pp. 123-130, November 2016, DOI: http://dx.doi.org/10.26555/ijain.v2i3.59.

This paper has been found to be in violation of the International Journal of Advances in Intelligent Informatics Publication principles and has been retracted.

The article contained redundant material, the editor investigated and found that the paper published in International Journal of Grid and Distributed Computing, Vol. 9, No. 11, pp. 61-70, 2016, DOI: http://dx.doi.org/10.14257/ijgdc.2016.9.11.05.

The document and its content has been removed from International Journal of Advances in Intelligent Informatics, and reasonable effort should be made to remove all references to this article.

Copyright $\odot 2017$ International Journal of Advances in Intelligent Informatics. All rights reserved. 